\title{
Association Between Weight Gain, Psychological, Sociodemographic Factors, and Physical Activity in Bariatric Patients: A Network Perspective
}

\section{Nélio Barreto Vieira}

Faculdade de Medicina da Fundacao do ABC: Faculdade de Medicina do ABC

Paulo Felipe Ribeiro Bandeira ( $\square$ paulo.bandeira@urca.br)

Universidade Regional do Cariri

Gyllyandeson Delmondes

Universidade Regional do Cariri https://orcid.org/0000-0002-9890-9196

Rafaela Bertoldi

Universidade Federal do Rio Grande do Sul

Glacithane Lins da Cunha

Universidade Regional do Cariri

Nayara da Silva Soares

Universidade Regional do Cariri

\section{Lara Belmudes Bottcher}

Faculdade Leão Sampaio: Centro Universitario Doutor Leao Sampaio

Roberto Lopes de Almeida

Faculdade de Medicina da Fundacao do ABC: Faculdade de Medicina do ABC

Maria Eveline Vieira

Faculdade de Juazeiro do Norte

Sedigheh Salami

Alzahra University

Marta Regina Kerntopf

Universidade Regional do Cariri

Clarice Martins

Universidade Do Porto

\section{Victor Zaia}

Faculdade de Medicina da Fundacao do ABC: Faculdade de Medicina do ABC

\section{Research Article}

Keywords: Obesity, Bariatric surgery, Adaptive complex system, Network analysis 
Posted Date: May 24th, 2021

DOl: https://doi.org/10.21203/rs.3.rs-515748/v1

License: (c) (i) This work is licensed under a Creative Commons Attribution 4.0 International License. Read Full License 


\section{Abstract}

Background Weight gain affects about $10-20 \%$ of patients after bariatric surgery (BS). It's a phenomenon that's difficult to understand and to intervene due to its complexity and etiological heterogeneity. In the present study, we investigated, from a network analysis perspective, the associations between weight regain, psychological, sociodemographic factors and physical activity in patients undergoing BS.

Methods The sample consisted of 124 patients, of both sexes, aged $39 \pm 9.1$ years, who had undergone surgical intervention for more than 18 months. After voluntary consent, respondents answered questionnaires and instruments directly on the Google Forms platform.

Results The weight gain was negatively associated with the items of depression, anxiety and stress, binge eating and with the dimensions of the personality questionnaire (negative affectivity -0.182 ; detachment -0.078; antagonism -0.107; disinterest - 0.198 and psychoticism -0.158).

Conclusion Characteristics of disinterest and negative affectivity and most of the items on the depression, anxiety and stress scale had a greater expected influence, indicating that these are the most sensitive variables to intervention and who need more attention from health professionals.

Level of evidence: Level III, evidence obtained from well-designed case-control analytic studies.

\section{Introduction}

Obesity is a worldwide epidemic. In 2016, more than 1.9 billion adults were overweight and of these, more than 650 million were obese [1]. Morbid obesity is the most severe form of this disease, reducing life expectancy between 10 and 15 years [2]. This pathology is defined as a metabolic disease of genetic etiology and aggravated by exposure to environmental, psychological, cultural, economic, social phenomena. Still being associated with factors such as age, race, gender, and sedentary lifestyle, proving its multifactoriality and complexity [3-4].

Clinical treatment for obesity includes nutritional therapy, medication and physical activity. When there is failure in this treatment and obesity becomes morbid, BS is indicated [5]. Unfortunately, in an average period of 18 months after surgery, $10-20 \%$ of operated patients gain weight [6-8]. Eating behavior, sedentary lifestyle, and psychological factors such as depression, anxiety, stress, binge eating, personality, body self-image, and how the individual faces external stress factors, may be listed as the several factors that influence weight gain. Indeed, patients with anxious behaviors tend to eat more after BS, and those with greater capacity for concentration, organization and systematic control would likely avoid weight gain [9]. These characteristics may be linked to the evaluation that individuals have about eating behavior. Studies have even indicated that this failure of evaluative capacity is one of the best predictors of weight gain, once the patient does not perceive what he eats, how much he eats, what habits are healthy, including physical activity, and which are not [10-12]. Though all these factors seem to be intrinsically related in the same individual, the relationship among them is still unclear [6]. 
Failure to maintain weight loss after BS has been the subject of study in different clinical trials, in order to predict possible influencing factors in outcomes in people with obesity before and after surgical intervention [16]. Studies have shown that among the different factors involved in weight regain, preoperative and postoperative psychological distress are related to eating behaviors and weight maintenance after BS, [13-15]. However, systematic review research [14] and meta-analysis [15] claim that the evidence on the association between emotional conditions and preoperative eating disorders and postoperative weight loss is inconsistent. Therefore, in order to investigate the interaction between personality traits, anxiety and eating symptoms in obese candidates for BS, Monteleone et al. [17] demonstrated, for the first time in a network analysis perspective, the influences between personality traits and anxiety symptoms on eating behaviors in this group of patients; however, the authors state that the main limitation of that study was the failure to include depressive symptoms and social measures in their analyzes.

Therefore, considering the aforementioned attributes, the problem of obesity and weight gain can be characterized as a complex system (SCA). Complex systems have heterogeneous agents that interact in a non-linear way and are sensitive to small changes. In this sense, the perspective of networks can be proposed as an excellent tool to evaluate complex systems, as in the health area [18] and specifically in obesity [19]. Thus, the present study aimed to evaluate possible associations between weight regain, psychological (anxiety, stress, depression and personality), sociodemographic factors and physical activity from a network perspective in patients undergoing BS.

\section{Materials And Methods}

This is a quantitative and cross-sectional study. The STROBE protocol [20] and CHERRIES [21] were used. The sample was composed of convenience. Inclusion criteria were: patients aged at least 18 years old, of both sexes, operated by the same surgeon, by Gastric Bypass or Sleeve techniques and who accepted to voluntarily participate in the study. Patients with post-surgical time less than 18 months were excluded from the sample. Invitations were sent to bariatric patients Brazilians over 18 months old, of which only 124 voluntarily agreed to participate in the research, and it is emphasized that of this total $14.5 \%$ of the patients were operated by the Sleeve technique and $85.5 \%$ by the Bypass technique. The individuals in the sample had a mean age of $39 \pm 9.1$ years, of both sexes, with a minimum post-surgical time of 18 months and a maximum of 144 months, followed by the multidisciplinary health team of the Nucleus Health Services located in the municipality of Ceará, Brazil. An online invitation to participate in this study was directed individually to each participant, where they were informed about the objectives, protocols and procedures of the research. After voluntary consent, the interviewees answered the instruments directly on the Google Forms online platform. The Helsinki Declarations' ethical aspects were followed. This study was approved by the Brazil National Board of Research Ethics under the requirement of proper informed consent.

\section{Measures}


A questionnaire was used to obtain information on the clinical and socioeconomic variables. Two instruments were applied: Bulimic Investigatory Test of Edinburgh (BITE) [22], in its version in Portuguese [23], and the Periodic Binge Eating Scale (ECAP) [24] also in its Brazilian version [25]. The BITE is a selfadministered questionnaire, composed of two scales: one of symptoms (composed of 30 items) and one of severity (3 dimensional items). [22-23]. ECAP is an appropriate instrument to distinguish individuals who are candidates for BS according to the severity of 'periodic binge eating' (CAP) [26]. BMI (body mass index) was calculated by dividing body mass by square of height in meters $\left(\mathrm{Kg} / \mathrm{m}^{2}\right)$. To evaluate weight loss and regained weight after surgery, the equation of \%TWL (Percent total weight loss) was used, considered one of the best methods to evaluate post-bariatric weight loss. Values higher than $15 \%$ of NADIR weight (lower body weight achieved after bariatric powders) [27-28] is considered weight regain [27]. The level of physical activity (PA) was assessed using the summarized version of the International Physical Activity Questionnaire (IPAQ) validated in Brazil by Matsudo et al. [29-30]. Symptoms of stress, anxiety and depression were measured and differentiated using the Depression, Anxiety and Stress Scale - Short Form (DASS-21) instrument [31]. In this study, the DASS-21 version was used for Brazilian adults translated and valid by Machado and Bandeira [32]. [33]. Pathological personality traits were evaluated using the Personality Inventory for DSM-5 Short Form (PID-5-SF) [34]. It is a self-applicable instrument composed of 100 items extracted from the Personality Inventory for DSM-5 (PID-5) [35], which was reduced and validated by Timm et al. [32]. The scores of the PID-5-SF domains are calculated by adding scores from the three scales that contribute to the evaluation of the pathological personality traits of the hybrid model proposed by the DSM-5 [35-36].

\section{Statistical analysis}

Means and standard deviations were used for continuous variables and frequency distributions (absolute and relative values) for categorical variables. To compare age between the group with weight regain and without weight regimen, the $t$ test for independent samples was used. The other categorical variables were compared between patients with and without weight regain and between sex using the chi-square test. P-value $<0.05$ was considered significant. A network analysis was used to evaluate the association between biological and psychosocial variables. Indicators of closeness and expected influence were reported. Variables with higher expected influence values are more sensitive to change and can act as a hub by connecting other pairs of variables on the network. A variable with a high closeness value will be quickly affected by changes anywhere in the network and can also affect other parts. To improve network accuracy, we use the "Markov random fields in pairs" model. The algorithm adds a penalty "L1" (regularized neighborhood regression). The adjustment is estimated by a less complete selection and contraction operator (Lasso) that controls the sparse network. The extended Bayesian information criterion (EBIC) was observed to select the Lambda from the regularization parameter. Network analysis uses regularized algorithms of lower absolute reduction and selection operator (LASSO) to obtain the precision matrix. This matrix, when standardized, represents the associations between the variables present in the network. The blue color represents positive associations, and the red color represents negative associations. The thickness and intensity of colors represent the magnitude of the associations. The analyses were performed through the RStudio and package qgraph. 


\section{Results}

Sociodemographic characteristics and reported PA levels of participants with and without weight gain by sex are presented in Table 1. In the weight gain group $(\mathrm{N}=42)$, most of the participants were female $(\mathrm{N}=$ 97), satisfied with the current weight (71.4\%). Only in the income variable was found a statistically significant difference between the group with and without weight gain $(x 2=13.58 ; p=0.009)$. 
Table 1

Characteristics of the participants.

\begin{tabular}{|c|c|c|c|c|c|c|}
\hline \multirow[t]{3}{*}{ Variable } & \multicolumn{2}{|c|}{$M(S D)$ ou $N(\%)$} & \multicolumn{2}{|c|}{$M(S D)$ or $N(\%)$} & \multirow{3}{*}{$\begin{array}{l}t \text { ou } \\
x^{2}\end{array}$} & \multirow{3}{*}{$\begin{array}{l}\mathrm{p}- \\
\text { value }\end{array}$} \\
\hline & \multicolumn{2}{|c|}{ Regain $(N=42)$} & \multicolumn{2}{|c|}{ Without regain $(\mathrm{N}=82)$} & & \\
\hline & $\begin{array}{l}\text { Men }(\mathrm{N}= \\
10)\end{array}$ & $\begin{array}{l}\text { Woman }(\mathrm{N} \\
=32)\end{array}$ & $\begin{array}{l}\text { Men }(N= \\
17)\end{array}$ & $\begin{array}{l}\text { Woman }(\mathrm{N}= \\
65)\end{array}$ & & \\
\hline Age (years old) & $35.2(6.05)$ & $38.93(9.96)$ & $40.7(7.93)$ & $39.96(10.46)$ & -1.13 & 0.26 \\
\hline \multicolumn{7}{|c|}{$\begin{array}{l}\text { Satisfaction with current } \\
\text { weight N (\%) }\end{array}$} \\
\hline Dissatisfied & $2(20)$ & $10(31)$ & $8(47)$ & $30(46)$ & \multirow[t]{2}{*}{3.64} & \multirow[t]{2}{*}{0.056} \\
\hline Satisfied & $8(80)$ & $22(69)$ & $9(53)$ & $35(54)$ & & \\
\hline \multicolumn{7}{|l|}{$\begin{array}{l}\text { People in the house } \mathrm{N} \\
(\%)\end{array}$} \\
\hline 1 & $1(10)$ & $11(34)$ & $1(5.9)$ & $14(22)$ & \multirow[t]{5}{*}{3.37} & \multirow[t]{5}{*}{0.49} \\
\hline 2 & $3(30)$ & $4(12.5)$ & $2(11.76)$ & $15(23)$ & & \\
\hline 3 & $4(40)$ & $8(25)$ & $11(64.70)$ & $21(32)$ & & \\
\hline 4 & $2(20)$ & $5(16)$ & $3(17.64)$ & 11(17) & & \\
\hline 5 & $0(0)$ & $4(12.5)$ & $0(0)$ & $4(6)$ & & \\
\hline \multicolumn{7}{|l|}{ Income N (\%) } \\
\hline Up to 380 USD & $0(0)$ & $3(9)$ & $1(6)$ & $1(1)$ & \multirow[t]{5}{*}{13.58} & \multirow[t]{5}{*}{0.009} \\
\hline 380 USD to 760 USD & $1(10)$ & $5(16)$ & $1(6)$ & $18(28)$ & & \\
\hline 760USD to 1900 USD & $6(60)$ & 19(59) & $3(18)$ & $22(34)$ & & \\
\hline 1900 USD to 3800 USD & $2(20)$ & $5(16)$ & $10(59)$ & $24(37)$ & & \\
\hline Over 3800USD & $1(10)$ & $0(0)$ & $2(11)$ & $0(0)$ & & \\
\hline \multicolumn{7}{|l|}{$\begin{array}{l}\text { Schooling (in years) } \mathrm{N} \\
\text { (\%) }\end{array}$} \\
\hline 9 & $4(40)$ & $14(44)$ & 10(59) & $16(25)$ & \multirow[t]{3}{*}{1.80} & \multirow[t]{3}{*}{0.40} \\
\hline 12 & $6(60)$ & $18(56)$ & $7(41)$ & $47(72)$ & & \\
\hline$\geq 16$ & $0(0)$ & $0(0)$ & $0(0)$ & $2(3)$ & & \\
\hline \multicolumn{7}{|l|}{ Physical activity } \\
\hline Inactive & $3(30)$ & $13(41)$ & $4(24)$ & $17(26)$ & 2.06 & 0.15 \\
\hline
\end{tabular}




\begin{tabular}{|llllll|}
\hline Variable & $\mathrm{M}(\mathrm{SD})$ ou $\mathbf{N}(\%)$ & $\mathrm{M}(\mathrm{SD})$ or $\mathbf{N}(\%)$ & $\begin{array}{l}\text { t ou } \\
\mathbf{x}^{2}\end{array}$ & $\begin{array}{l}\text { p- } \\
\text { value }\end{array}$ \\
\hline Active & $7(70)$ & $19(59)$ & $13(76)$ & $48(74)$ & \\
\hline
\end{tabular}

\section{Network Analysis}

The main results of the network indicated that weight regain was negatively associated with all items of depression, anxiety and stress, with the items of binge eating, and with the dimensions of the personality questionnaire (negative affectivity - 0.182; distancing - 0.078; Antagonism - 0.107; Disinhibition - 0.198 and Psychoticism - 0.158). The regain is also associated with having a lower income $(-0.292)$ and having a better schooling (0.255).

\section{Centrality measures}

Table 2 shows the network centrality measures. The personality characteristics: disinterest and negative affectivity and most items of the depression, anxiety and stress scale (D3 "I could not have positive feelings", D5 "I found it difficult to have initiative to do things", D8 "I felt i was quite nervous", D9 "I was worried about situations where I could panic and make a fool of myself", D10 "I felt I had no positive expectations about anything", D11 "I noticed i was getting agitated", D12 "I found it difficult to relax", D13" I felt downcast and sad", D14 "I didn't have patience with anything that interrupted what I was doing", D15 " I felt I was about to panic", D16 " I couldn't get carried away with anything", D17 "I felt i didn't have much value as a person", D18 "I felt that I was very angry", D20 "I felt scared without any reason" and D21 "I felt that life had no meaning".) had greater expected influence, ranging from 1,043 to 1,502.

The variables with the highest values of closeness were, Ec3, Ec7, Ec9, Ec10, Ec11, D14, Bite_8 "Does your eating pattern severely harm your life?", Bite_10 "Do you eat non-stop until you are forced to stop feeling physically unwell?", Bite_11"Are there times when you can only think about food?", Bite_14 "Have you ever felt an uncontrollable urge to eat and eat non-stop?", Bite_15 "When do you feel anxious), tend to eat too much?", Bite_18 "Are you ashamed of your eating habits?", Bite_31 "Your eating habits are what you might consider normal?" and Bite_32 "Do you consider yourself someone who eats compulsively?", ranging from 1,004 to 1,968 . 
Table 2

Network centrality measures.

\begin{tabular}{|c|c|c|}
\hline & Closeness & Expected Influence \\
\hline Gender & -1.730 & -0.315 \\
\hline Regain & -0.490 & -1.646 \\
\hline AGE & -1.736 & -0.424 \\
\hline Negative Affectivity & 1.389 & 1.267 \\
\hline Distancing & 0.087 & 0.878 \\
\hline Antagonism & -0.773 & 0.347 \\
\hline Disinterest & 0.790 & 1.071 \\
\hline Psychoticism & -0.303 & 0.910 \\
\hline Ec1 & 0.775 & 0.328 \\
\hline Ec2 & -1.554 & -0.481 \\
\hline Ec3 & 1.968 & 0.730 \\
\hline Ec4 & 0.964 & 0.369 \\
\hline Ec5 & 0.699 & 0.650 \\
\hline Ec6 & 0.965 & 0.119 \\
\hline Ec7 & 1.186 & 0.828 \\
\hline Ec8 & 0.340 & 0.285 \\
\hline Ec9 & 1.297 & 0.393 \\
\hline Ec10 & 1.812 & 0.990 \\
\hline Ec11 & 1.013 & 0.636 \\
\hline Ec12 & -0.515 & -0.609 \\
\hline Ec13 & -1.120 & -0.519 \\
\hline Ec14 & -0.179 & -0.008 \\
\hline Ec15 & 0.451 & 0.244 \\
\hline Ec16 & 0.282 & 0.555 \\
\hline D1 & -0.392 & 0.747 \\
\hline D2 & -1.609 & -0.098 \\
\hline
\end{tabular}




\begin{tabular}{|c|c|c|}
\hline & Closeness & Expected Influence \\
\hline D3 & 0.810 & 1.190 \\
\hline D4 & -0.615 & 0.497 \\
\hline D5 & 0.292 & 1.043 \\
\hline D6 & -0.479 & 0.786 \\
\hline D7 & -0.814 & 0.726 \\
\hline D8 & -0.168 & 1.301 \\
\hline D9 & -0.073 & 1.126 \\
\hline D10 & 0.833 & 1.370 \\
\hline D11 & -0.077 & 1.248 \\
\hline D12 & 0.459 & 1.357 \\
\hline D13 & 0.340 & 1.296 \\
\hline D14 & 1.117 & 1.290 \\
\hline D15 & 0.254 & 1.502 \\
\hline D16 & 0.733 & 1.374 \\
\hline D17 & 0.707 & 1.291 \\
\hline D18 & 0.635 & 1.281 \\
\hline D19 & -0.609 & 0.894 \\
\hline D20 & 0.003 & 1.383 \\
\hline D21 & 0.276 & 1.564 \\
\hline Bite1 & -0.848 & 0.251 \\
\hline Bite2 & -0.877 & 0.538 \\
\hline Bite3 & 0.246 & -0.987 \\
\hline Bite4 & -0.544 & 0.189 \\
\hline Bite5 & -1.316 & -1.025 \\
\hline Bite7_1 & -1.256 & -0.412 \\
\hline Bite7_2 & -1.136 & -0.572 \\
\hline Bite7_3 & -1.228 & -0.352 \\
\hline Bite7_4 & -1.156 & -0.208 \\
\hline
\end{tabular}




\begin{tabular}{|c|c|c|}
\hline & Closeness & Expected Influence \\
\hline Bite_8 & 1.269 & -1.672 \\
\hline Bite_9 & 0.527 & -1.071 \\
\hline Bite_10 & 1.004 & -1.743 \\
\hline Bite_11 & 1.376 & -1.762 \\
\hline Bite_12 & 0.511 & -1.159 \\
\hline Bite_13 & 0.853 & 0.387 \\
\hline Bite_14 & 1.224 & -1.706 \\
\hline Bite_15 & 1.069 & -1.488 \\
\hline Bite_16 & -0.192 & -1.337 \\
\hline Bite_17 & -0.818 & -0.770 \\
\hline Bite_18 & 1.211 & -1.581 \\
\hline Bite_19 & 0.444 & -0.857 \\
\hline Bite_20 & 0.638 & -1.229 \\
\hline Bite_21 & 0.733 & 0.749 \\
\hline Bite_22 & 0.490 & -1.248 \\
\hline Bite_23 & -1.940 & -0.060 \\
\hline Bite_24 & -0.304 & -0.975 \\
\hline Bite_25 & -0.652 & -0.777 \\
\hline Bite_26 & -1.759 & -0.356 \\
\hline Bite_27 & 0.465 & 0.386 \\
\hline Bite_28 & -0.443 & -1.314 \\
\hline Bite_29 & -0.399 & -0.470 \\
\hline Bite_30 & 0.603 & -1.230 \\
\hline Bite_31 & 1.731 & 0.683 \\
\hline Bite_32 & 1.041 & -1.605 \\
\hline Bite_33 & -0.656 & -1.035 \\
\hline Income & -1.881 & -1.261 \\
\hline People in the house & -2.372 & -0.389 \\
\hline
\end{tabular}




\begin{tabular}{|lll|}
\hline & Closeness & Expected Influence \\
\hline Schooling & -1.660 & -0.930 \\
\hline Current Weight Satisfaction & -0.362 & 0.073 \\
\hline Physical Activity Level & -0.876 & -1.440 \\
\hline
\end{tabular}

\section{Discussion}

The aim of this study was to evaluate the possible associations between personality, psychological, sociodemographic factors, physical activity, eating behavior and the influences of these variables on weight regain of patients undergoing BS, considering the interactions between these variables in an adaptive complex system measured in a network analysis, characterizing a novelty in the literature.

Our findings revealed that there is a negative relationship between weight gain and personality traits: disinterest and negative affectivity (PID-5-SF) and these are associated with depressive, anxiety and stress behaviors (DASS 21) reflecting on bulimic and/or compulsive eating behavior (BITE and ECAP). The literature is scarce in the investigation between changes in eating behavior and weight recovery after BS [37-38]. However, some studies have observed that the mental health of the patient is one of the most important factors in the maintenance and weight gain after surgical intervention [39-41]. In this sense, the occurrence of binge eating in obese candidates for BS is frequent [42-44]. In the study by Cella et al. [44], the authors observed that the prevalence of periodic compulsive eating disorders in candidates for BS ranges from 2 to $49 \%$ [45].

Although different authors claim that the occurrence of binge eating, depression and anxiety are not predictive factors regarding the magnitude of weight loss and maintenance or recurrence of compulsive disorders after BS [46-48], our findings reveal that there is a negative relationship between weight gain and symptoms that suggest personality traits associated with depressive, anxiety and stress behaviors, which, consequently, correlate with periodic compulsive eating disorders. Similar studies, although with different statistical perspectives, demonstrate that risk factors that compromise physical and psychological well-being, both in the preoperative period and in the postoperative period of BS, are associated with unbalanced diet, lack of physical activity and psychological disorders [48]. For example, the study by Figueiredo et al. [49], who investigated the types of personalities in obese women and postBS, reported that participants with introverted attitudes showed a higher prevalence of severe binge eating, recent and lifelong suicidal thoughts, when compared to participants extrovert. In this perspective, the study by Freire et al. [38] observed that obese candidates for BS with episodes of binge eating have a high prevalence of depressive and anxious symptoms.

In our study beyond personality, depression, anxiety and stress, we added information about and how these psychological factors act in a network with sociodemographic factors, binge eating, physical activity and weight gain in patients 18 to 144 months after BS. Our findings revealed that bariatric 
patients who have a lower income and better education have a greater weight regain. With regard to the association between income and overweight, similar data have been reported in previous studies, which state that a higher socioeconomic level is related to a lower risk of obesity [50-52-53]. In addition, the literature demonstrates a relationship between income and a healthier lifestyle, as people who have a higher income are more likely to practice physical activity and follow a dietary follow-up [54-56].

The factors that predict the susceptibility of patients to weight gain after BS are not fully known [38]. Studies state that weight recovery is a multifactorial process of complex etiology [56-57]. In our study we also investigated through an analysis of weight gain networks, which are the most sensitive factors to interventions from network indicators. We found that the items referring to personality characteristics: disinterest and negative affectivity and most items of the depression, anxiety and stress scale presented high expected influence, these items need to be urgently treated in these patients by professionals from different areas. We also elucidate from the indications of closenness centrality that the items of binge eating will be the most benefited from multidisciplinary interventions, which indicates that the treatment of patients with weight gain in the present study should focus on these psychological aspects, which, consequently, would improve the compulsive eating behavior.

Another point of limitation refers only to patients after BS (18 to 144 months post-surgery), since it is necessary to analyze the different preoperative and postoperative factors that possibly affect the loss process and weight regain, which would allow a more effective perioperative follow-up.

\section{Conclusion}

The current results indicated that binge eating items could be the most benefited from inventions in psychological aspects to avoid weight gain in the postoperative period of bariatric patients. The present study provides a new approach to evaluate interactions between weight gain and its correlates, as a complex adaptive system. Although complex systems are difficult to intervene, this study highlights important subside to plan complex interventions in complex systems, based on the centrality indicators.

\section{Declarations}

Conflicts of Interest: The authors declare no conflict of interest.

\section{References}

1. World Health Organization - WHO (2020) Obesity and overweight. https://www.who.int/newsroom/fact-sheets/detail/obesity-and-overweight. Accessed 21 September 2020

2. Fontaine KR, Redden DT, Wang C, Westfall AO, Allison DB (2009) Years of life lost due to obesity. JAMA 289:187-193. https://doi:10.1001/jama.289.2.187

3. Hammond RA (2009). Complex systems modeling for obesity research. Prev Chronic Dis 6:A97. ). http://www.cdc.gov/pcd/issues/2009/jul/09_0017. Acessed 19 September 2020 
4. Jantaratnotai N, Mosikanon K, Lee Y, Mclntyre RS (2017) The interface of depression and obesity. Obes Res Clin Pract 11:1-10. https:// 10.1016/j.orcp.2016.07.003

5. Baltieri L, Santos LAD, Rasera-Junior I, Montebelo MIDL, Pazzianotto-Forti EM (2015) Use of posi-tive pressure in preoperative and intraoperative of BS and its effect on the time of extubation. Rev Bras Anestesiol 65:130-135. http://dx.doi.org/10.1016/j.bjane.2013.10.021

6. Freire RH, Borges MC, Alvarez-Leite JI, Correia MITD (2012) Food quality, physical activity and nutritional follow-up as determinant of weight regain after Roux-en-Y gastric Bypass. Nutrition 28:5358. https:// 10.1016/j.nut.2011.01.011

7. Magro DO, Geloneze B, Delfini R, Pareja BC, Callejas F, Pareja JC (2008) Long-term weight regain after gastric bypass: a 5-year prospective study. Obes Surg 18:648-651. https:// 10.1007/s11695007-9265-1

8. Sjöström L, Narbro K, Sjöström CD, Karason K, Larsson B, Wedel H, Lystig T, Sullivan M, Bou-chard C, Carlsson B, Bengtsson C, Dahlgren S, Gummesson A, Jacobson P, Karlsson J, Lindroos AK, Lönroth H, Näslund I, Olbers T, Stenlöf K, Torgerson J, Agren G, Carlsson LM (2017) Effects of bariatric 244 surgery on mortality in Swedish obese patients. N Engl J Med 357:741-752. https://10.1056/NEJMoa066254

9. Gade H, Friborg O, Rosenvinge J, Småstuen M, Hjelmesæth J (2015) The Impact of a Preoperative Cognitive Behavioural Therapy (CBT) on Dysfunctional Eating Behaviours, Affective Symptoms and Body Weight 1 Year after BS: A Randomised Controlled Trial. Obes Surg 25:2112-2119. https://10.1007/s11695-015-1673-z

10. Byrne SM, Cooper Z, Fairburn CG (2004) Psychological predictors of weight regain in obesity. Behav Res Ther 42:1341-1356. https://10.1016/j.brat.2003.09.004

11. da-Luz FQ, Swinbourne J, Sainsbury A, Touyz S, Palavras M, Claudino A, Hay P (2017) Hapifed: A healthy approach to weight management and food in eating disorders: A case series and manual development. J Eat Disord 5:1-11. https://doi.org/10.1186/s40337-017-0162-2

12. Bottcher LB, Bandeira PFR, Vieira NB, Zaia V, Lopes DAR (2020) Quality of Life, BMI, and Physi-cal Activity in BS Patients: a Structural Equation Model. Obes Surg 30:2927-2934. https://10.1007/s11695-020-04615-z

13. Claes W, Vandereycken L, Vandeputte A, Braet C (2013) Personality subtypes in female pre-bariatric obese patients: do they differ in eating disorder symptoms, psychological complaints and coping behaviour? Eur Eat Disord Rev 21:72-77. https://10.1002/erv.2188

14. Livhits M, Mercado C, Yermilov I, Parikh JA, Dutson E, Mehran A, Ko CY, Gibbons MM (2012) Preoperative predictors of weight loss following BS: systematic review. Obes Surg ;22:70-89. https://10.1007/s11695-011-0472-4.

15. Dawes AJ, Maggard-Gibbons M, Maher AR, Booth MJ, Miake-Lye I, Beroes JM, Shekelle PG (2016) Mental Health Conditions Among Patients Seeking and Undergoing BS: A Meta-analysis. J 315(2):150-163. https://10.1001/jama.2015.18118. 
16. Conceição EM, Fernandes M, de Lourdes M, Pinto-Bastos A, Vaz AR, Ramalho S (2020) Perceived social support before and after BS: association with depression, problematic eating behaviors, and weight outcomes. Eat Weight Disord25:679-692. https://10.1007/s40519-019-00671-2.

17. Monteleone AM, Cascino G, Solmi M, Pirozzi R, Tolone S, Terracciano G, Parisi S, Cimino M, Monteleone P, Maj M, Docimo L (2019) A network analysis of psychological, personality and eating characteristics of people seeking BS: Identification of key variables and their prognostic value. J Psychosom Res120:81-89. https://10.1016/j.jpsychores.2019.03.010.

18. Caldarelli GA (2020) Perspective on Complexity and Networks Science. J Phys Complex 1:1-5. https://10.1088/2632-072x/ab9a24

19. Hammond RA (2009). Complex systems modeling for obesity research. Prev Chronic Dis 6(3):A97.

20. Strengthening the reporting of observational studies in epidemiology - STROBE STATEMENT (2007) STROBE checklists. https://www.strobestatement.org/fileadmin/Strobe/uploads/checklists/STROBE_checklist_v4_cross-sectional.pdf. Accessed 1 December 2020

21. Eysenbach G (2004) Improving the quality of Web surveys: the Checklist for Reporting Results of Internet E-Surveys (CHERRIES). J Med Internet Res 6(3):e34. https://10.2196/jmir.6.3.e34.

22. Henderson M, Freeman CP (1987) A self-rating scale for bulimia. The 'BITE'. Br J Psychiatry 150:1824. https://10.1192/bjp.150.1.18.

23. Cordás TA, Hpchgraf PB (1993) O "BITE": instrumento para avaliação da bulimia nervosa versão para o português. J Bras Psiquiatr 42:141-144.

24. Gormally J, Black S, Daston S, Rardin D (1982) The assessment of binge eating severity among obese persons. Addict Behav 7(1):47-55. https://10.1016/0306-4603(82)90024-7.

25. Freitas S, Lopes CS, Coutinho W, Appolinário JC (2001) Tradução e adaptação para o português da Escala de Compulsão Alimentar Periódica. J Bras Psiquiatr 23:215-220. https://doi.org/10.1590/S1516-44462001000400008.

26. Grupski AE, Hood MM, Hall BJ, Azarbad L, Fitzpatrick SL, Corsica JA (2013) Examining the Binge Eating Scale in screening for binge eating disorder in BS candidates. Obes Surg 23(1):1-6. https://10.1007/s11695-011-0537-4.

27. Voorwinde V, Steenhuis IHM, Janssen IMC, Monpellier VM, van Stralen MM (2020) Definitions of Long-Term Weight Regain and Their Associations with Clinical Outcomes. Obes Surg 30(2):527-536. https:10.1007/s11695-019-04210-x.

28. Sjöström L (2013) Review of the key results from the Swedish Obese Subjects (SOS) trial - a prospective controlled intervention study of BS. J Intern Med 273(3):219-34. https://10.1111/joim.12012.

29. Matsudo S, Araújo T, Matsudo V, Andrade D, Andrade E, Oliveira LC, Braggion G (2001) Questinário internacional de atividade física (IPAQ): estudo de validade e reprodutibilidade no Brasil. Rev Bras Ativ Fís Saúde 2:5-18. https://doi.org/10.12820/rbafs.v.6n2p5-18 
30. Marshall A, Bauman A (2001) The international physical activity questionnaire: summary report of the reliability\& validity studies. IPAQ Executive Committee 1-25.

31. Lovibond PF, Lovibond SH (1995) The structure of negative emotional states: comparison of the Depression Anxiety Stress Scales (DASS) with the Beck Depression and Anxiety Inventories. Behav Res Ther 33(3):335-343. https://10.1016/0005-7967(94)00075-u.

32. Machado WL, Bandeira DR (2013). Adaptação e validação da Depression, Anxiety and Stress Scale (DASS-21) para o Português brasileiro. Manuscript submitted for publication.

33. Watson D, Weber K, Assenheimer JS, Clark LA, Strauss ME, McCormick RA (1995) Testing a tripartite model: I. Evaluating the convergent and discriminant validity of anxiety and depression symptom scales. J Abnorm Psychol 104(1):3-14. https://10.1037//0021-843x.104.1.3.

34. Barchi-Ferreira AM, Loureiro SR, Torres AR, Da Silva TDA, Moreno AL, De Sousa DA, Osório FL (2019) Personality Inventory for DSM-5 (PID-5): cross-cultural adaptation and content validity in the Brazilian context. Trends Psychiatry Psychother 41:297-300. https://doi.org/10.1590/2237-60892018-0098.

35. American Psychiatric Association - APA (2013) The Personality Inventory for DSM-5 (PID5)-Adult. https://www.psychiatry.org/File Library/Psychiatrists/Practice/DSM/APA_DSM5_The-PersonalityInventory-For-DSM-5-Full-Version-Adult.pdf. Accessed 2 April 2020

36. Thimm JC, Jordan S, Bach B (2016) The Personality Inventory for DSM-5 Short Form (PID-5-SF): psychometric properties and association with big five traits and pathological beliefs in a Norwegian population. BMC Psychol 4:61. https://10.1186/s40359-016-0169-5.

37. Devlin MJ, King WC, Kalarchian MA, Hinerman A, Marcus MD, Yanovski SZ, Mitchell JE (2018) Eating pathology and associations with long-term changes in weight and quality of life in the longi-tudinal assessment of BS study. Int J Eat Disord 51:1322-1330. https://10.1002/eat.22979.

38. Freire CC, Zanella MT, Segal A, Arasaki CH, Matos MIR, Carneiro G (2021) Associations between binge eating, depressive symptoms and anxiety and weight regain after Roux-en-Y gastric bypass surgery. Eat Weight Disord 26:191-199. https://10.1007/s40519-019-00839-w.

39. Pinto-Bastos A, de Lourdes M, Brandão I, Machado PPP, Conceição EM (2019) Weight loss trajectories and psychobehavioral predictors of outcome of primary and reoperative BS: a 2-year longitudinal study. Surg Obes Relat Dis 15:1104-1112. https://10.1016/j.soard.2019.04.018.

40. Odom J, Zalesin KC, Washington TL, Miller WW, Hakmeh B, Zaremba DL, Altattan M, Balasubramaniam M, Gibbs DS, Krause KR, Chengelis DL, Franklin BA, McCullough PA (2010) Behavioral predictors of weight regain after BS. Obes Surg 20:349-356. https://10.1007/s11695-0099895-6.

41. Scholtz S, Bidlake L, Morgan J, Fiennes A, El-Etar A, Lacey JH, McCluskey S (2007) Long-term outcomes following laparoscopic adjustable gastric banding: postoperative psychological sequelae predict outcome at 5-year follow-up. Obes Surg 17:1220-1225. https://10.1007/s11695-007-9212-1.

42. Dawes AJ, Maggard-Gibbons M, Maher AR, Booth MJ, Miake-Lye I, Beroes JM, Shekelle PG (2016) Mental Health Conditions Among Patients Seeking and Undergoing BS: A Meta-analysis. JAMA 
315:150-63. https://10.1001/jama.2015.18118.

43. Novelle JM, Alvarenga MS (2016) Cirurgia bariátrica e transtornos alimentares: Uma revisão integrativa. Braz. J. Psychiatry 65:262-285. http://dx.doi.org/10.1590/0047-2085000000133

44. Cella S, Fei L, D’amico R, Giardiello C, Allaria A, Cotrufo P (2019) Binge eating disorder and related features in BS candidates. Open Medicine 14:407-415. https://doi.org/10.1515/med-2019-0043

45. Meany G, Conceição E, Mitchell JE (2014) Binge eating, binge eating disorder and loss of control eating: effects on weight outcomes after BS. Eur Eat Disord Rev 22:87-91. https://10.1002/erv.2273.

46. Testa G, Granero R, Siragusa C, Belligoli A, Sanna M, Rusconi ML, Angeli P, Vettor R, Foletto M, Busetto L, Fernández-Aranda F, Schiff S (2020) Psychological predictors of poor weight loss following LSG: relevance of general psychopathology and impulsivity. Eat Weight Disord 25:1621-1629. https://10.1007/s40519-019-00800-x.

47. Pekkarinen T, Mustonen H, Sane T, Jaser N, Juuti A, Leivonen M (2016) Long-Term Effect of Gas-tric Bypass and Sleeve Gastrectomy on Severe Obesity: Do Preoperative Weight Loss and Binge Eating Behavior Predict the Outcome of BS? Obes Surg 26:2161-2167. https://10.1007/s11695-016-2090-7.

48. Cheroutre C, Guerrien A, Rousseau A (2020) Contributing of Cognitive-Behavioral Therapy in the Context of BS: a Review of the Literature. Obes Surg 30:3154-3166. https://10.1007/s11695-02004627-9.

49. de Figueiredo MDD, Nasser SN, Franco CB, Dos Santos CB, Boguszewski CL, Suplicy HL, Rodrigues AM, Radominski RB (2021) Personality type, eating behaviour and suicide risk in women in treatment for obesity. Eat Weight Disord 26:547-554. https://10.1007/s40519-020-00877-9.

50. Costa-Font M, Gil J, Traill B (2008) Consumer acceptance, valuation of and attitudes towards genetically modified food. Review and implications for food policy. Food Policy 33:99-111. https://doi.org/10.1016/j.foodpol.2007.07.002.

51. Wamala SP, Wolk A, Orth-Gomér K (1997) Determinants of obesity in relation to socioeconomic status among middle-aged Swedish women. Prev Med 26:734-44. https://10.1006/pmed.1997.0199.

52. Zhang Q, Wang Y (2007) Using concentration index to study changes in socio-economic inequality of overweight among US adolescents between 1971 and 2002. Int J Epidemiol 36:916-25. https://10.1093/ije/dym064.

53. Johnston DW, Lordan G (2014) Weight perceptions, weight control and income: an analysis using British data. Econ Hum Biol 12:132-139. https://10.1016/j.ehb.2013.02.004.

54. Pampel FC, Krueger PM, Denney JT (2010) Socioeconomic Disparities in Health Behaviors. Annu Rev Sociol 36:349-370. https://10.1146/annurev.soc.012809.102529.

55. Jeffery RW, French SA (1996) Socioeconomic status and weight control practices among 20- to 45year-old women. Am J Public Health 86:1005-1010. https://10.2105/ajph.86.7.1005.

56. Monpellier VM, Janssen IMC, Antoniou EE, Jansen ATM (2019) Weight Change After Roux-en Y Gastric Bypass, Physical Activity and Eating Style: Is There a Relationship? Obes Surg 29:526-533. https://10.1007/s11695-018-3560-x. 
57. Sarwer DB, Allison KC, Wadden TA, Ashare R, Spitzer JC, McCuen-Wurst C, LaGrotte C, Williams NN, Edwards M, Tewksbury C, Wu J (2019) Psychopathology, disordered eating, and impulsivity as predictors of outcomes of BS. Surg Obes Relat Dis 15(4):650-655. https://10.1016/j.soard.2019.01.029.

\section{Figures}

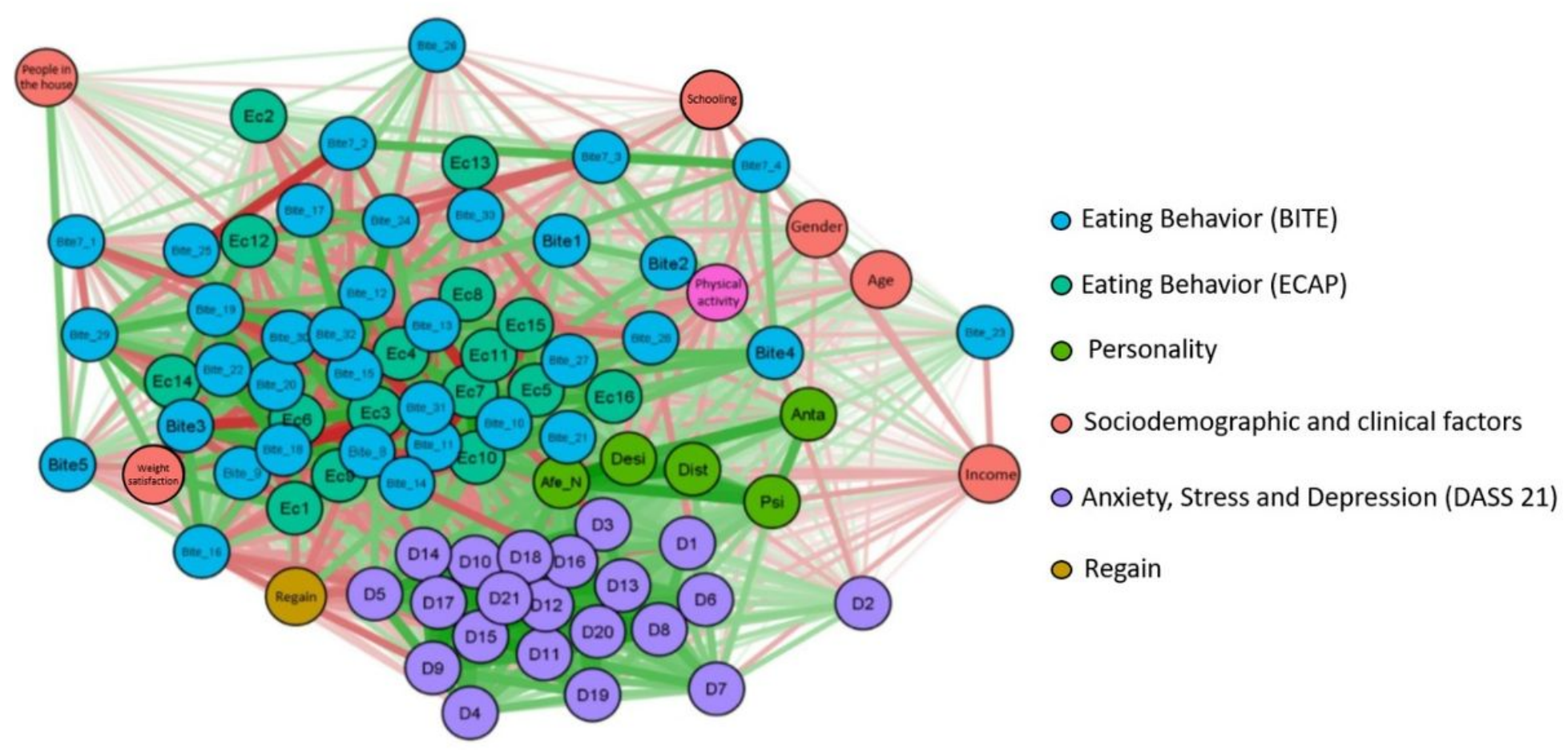

Figure 1

Associations between the variables weight gain, psychological factors (anxiety, stress, depression and personali-ty), sociodemographic and physical activity in bariatric patients.

\section{Supplementary Files}

This is a list of supplementary files associated with this preprint. Click to download.

- materialsuplementar.jpg 